\title{
Opportunities and Challenges for Improving the Patient Experience in the Acute and Post-Acute Care Setting Using Patient Portals: The Patient's Perspective
}

\author{
Anuj K. Dalal, MD ${ }^{1,2 \star}$, David W. Bates, MD, MSc ${ }^{1,2}$, Sarah Collins, RN, $\operatorname{PhD}^{1,2,3}$
}

${ }^{1}$ Brigham and Women's Hospital, Boston, Massachusetts; ${ }^{2}$ Harvard Medical School, Boston, Massachusetts; ${ }^{3}$ Partners Healthcare System, Wellesley, Massachusetts.

Efforts to improve the patient experience are increasingly focusing on engaging patients and their "care partners" by using patient portals. The Acute Care Patient Portal Task Force was supported by the Gordon and Betty Moore Foundation to convene a national meeting of an interdisciplinary group of stakeholders, including patient advocates, to consider how the acute and postacute care patient experience can be improved by using patient-facing technologies. We identified key opportunities and challenges for enhancing cognitive support, promoting respect while maintaining boundaries, and facilitating patient and family empowerment through the lens of the patient. Institutions, clinicians, and vendors would benefit tremendously by considering these 3 patient-centered themes when partnering with patients and family advisors to implement and realize the full potential of patient portals to enhance the acute and postacute care experience. Journal of Hospital Medicine 2017;12:1012-1016. Published online first October 18, 2017. (C) 2017 Society of Hospital Medicine
To realize the vision of patient-centered care, efforts are focusing on engaging patients and "care partners," often a family caregiver, by using patient-facing technologies. ${ }^{1-4}$ Web-based patient portals linked to the electronic health record (EHR) provide patients and care partners with the ability to access personal health information online and to communicate with clinicians. In recent years, institutions have been increasing patient portal offerings to improve the patient experience, promote safety, and optimize healthcare delivery. ${ }^{5-7}$

\section{DRIVERS OF ADOPTION}

The adoption of patient portals has been driven by federal incentive programs (Meaningful Use), efforts by the Center for Medicare and Medicaid Services, and the Office of the National Coordinator for Health Information Technology to improve patient outcomes and the transition toward value-based reimbursement. ${ }^{2,8,9}$ The vast majority of use has been in ambulatory settings; use for acute care is nascent at best. ${ }^{10}$ Among hospitalized patients, few bring an internet-enabled computer or mobile device to access personal health records online. ${ }^{11}$ However, evidence suggests that care partners will use portals on behalf of acutely ill patients. ${ }^{4}$ As the Caregiver Advise, Record, Enable Act is implemented, hospitals will be required to identify patients' care partners during hospitalization, inform them when the patient is ready for

\footnotetext{
*Address for correspondence and reprint requests: Anuj K. Dalal, MD, Assistant Professor, Harvard Medical School, Division of General Internal Medicine, Brigham and Women's Hospital, Brigham Circle, 1620 Tremont Street, Suite BC-3-002HH, Boston, MA 02120-1613; Telephone: 617-525-8891; Fax: $617-$ 732-7072; E-mail: adalal1@partners.org
}

Received: March 13, 2017; Revised: May 24, 2017; Accepted: May 30, 2017 2017 Society of Hospital Medicine DOI 10.12788/jhm.2860 discharge, and provide self-management instructions during the transition home..$^{12}$ In this context, understanding how best to leverage acute care patient portals will be important to institutions, clinicians, and vendors.

\section{CURRENT KNOWLEDGE}

The literature regarding acute care patient portals is rapidly growing. ${ }^{4,10}$ Hospitalized patients have unmet information and communication needs, and hospital-based clinicians struggle to meet these needs in a timely manner. ${ }^{13-15}$ In general, patients feel that using a mobile device to access personal health records has the potential to improve their experience. ${ }^{11}$ Early studies suggest that acute care patient portals can promote patient-centered communication and collaboration during hospitalization, including in intensive care settings. ${ }^{4,16,17}$ Furthermore, the use of acute care patient portals can improve perception of safety and quality, decrease anxiety, and increase understanding of health conditions. ${ }^{3,14}$ Although early evidence is promising, considerable knowledge gaps exist regarding patient outcomes over the acute episode of care. ${ }^{10,18}$

\section{OUTSTANDING QUESTIONS}

A clear area of interest is accessing acute care patient portals via mobile technology to engage patients during recovery from hospitalization. ${ }^{4,11}$ Although we do not yet know whether use during care transitions will favorably impact outcomes, given the high rate of harm after discharge, this seems likely. ${ }^{19}$ The few studies evaluating the effect on validated measures of engagement (Patient Activation Measure) and hospital readmissions have not shown demonstrable improvement to date. ${ }^{20,21}$ Clearly, optimizing acute care patient portals with regard to patient-clinician communication, as well as the type, timing, and format of information 
delivered, will be necessary to maximize value. ${ }^{4,22}$

From the patient's perspective, there is much we can learn. ${ }^{23}$ Is the information that is presented pertinent, timely, and easy to understand? Will the use of portals detract from face-to-face interactions? Does greater transparency foster more accountability? Achieving an appropriate balance of digital health-information sharing for hospitalized patients is challenging given the sensitivity of patient data when diagnoses are uncertain and treatments are in flux.,24 These questions must be answered as hospitals implement acute care patient portals.

\section{ACUTE CARE PATIENT PORTAL TASK FORCE}

To start addressing knowledge gaps, we established a task force of 21 leading researchers, informatics and policy experts, and clinical leaders. The Acute Care Patient Portal Task Force was a subgroup of the Libretto Consortium, a collaboration of 4 academic medical centers established by the Gordon and Betty Moore Foundation to design, develop, and implement technologies to engage patients, care partners, and providers in preventing harm in hospital settings. Initially, we were challenged with assessing stakeholders' perspectives from early adopter institutions. We learned that acute care patient portals must offer an integrated experience across care settings, humanize the patient-clinician relationship, enable equitable access, and align with institutional strategy to promote sustainability. ${ }^{19}$

In 2016, we convened the conference Acute Care Patient Portals 2020: Opportunities and Challenges for Development, Implementation, and Innovation. A total of 71 individuals participated, including chief medical informatics officers, chief nursing informatics officers, chief medical officers, chief nursing officers, quality and safety officers, executive directors, researchers, informatics experts, software developers, clinicians, patient and family advocates, entrepreneurs, policy leaders, and vendor representatives. The purpose of the meeting was multipronged; a key goal was to understand the patient's perspective during hospitalization. To achieve this, we led a panel composed of 3 patients who served on patient and family advisory councils at early adopter institutions. Panelists were asked to discuss how the use of patient-facing technologies could address current gaps. Meeting transcripts and notes were synthesized, summarized, and reviewed by task force members. By using a group consensus approach, we identified 3 main themes (Table 1). These themes confirm many of the opportunities and challenges reported in the literature but through the lens of the patient. We believe the insight gained will be valuable as institutions start implementing acute care patient portals.

\section{Cognitive Support}

The opportunities identified include acclimatizing and assimilating to the hospital environment (reviewing policies and patient rights) and facilitating self-education and preparation by linking to personal health information and providing structured guidance at transitions. ${ }^{4}$ For example, a care partner of an incapacitated patient may watch a video to orient to the intensive care unit, navigate educational content linked to the patient's admission diagnosis (pneumonia) entered in the EHR, view the timing of an upcoming imaging study (chest computed tomography scan), and complete a standardized checklist prior to discharge.

The main challenges we identified include ensuring accuracy of hospital-, unit-, and patient-level information, addressing information overload, configuring notification and display settings to optimize the user experience, presenting information at an appropriate health literacy level, ${ }^{4,21}$ and addressing security and privacy concerns when expanding access to family members. ${ }^{24}$

\section{Respect and Boundaries}

Opportunities identified include supporting individual learning styles by using interactive features of mobile devices to improve comprehension for visual, auditory, and tactile learners and reinforcing learning through the use of various types of digital media. ${ }^{25-27}$ For example, a visual learner may view a video tutorial for a newly prescribed medication. A tactile learner may prefer to use interactive graphical displays that exploit multidimensional touch capabilities of mobile devices to learn about active conditions or an upcoming procedure. An auditory learner may choose to use intelligent personal assistants to navigate their plan of care ("Hey Siri, what is my schedule for today?"). By addressing the learning preferences of patients and time constraints of clinicians, institutions can use acute care patient portals to promote more respectful interactions and collaborative decision-making during important care processes, such as obtaining surgical consent. ${ }^{28,29}$

We also identified opportunities to facilitate personalization by tailoring educational content and by enabling the use of patient-generated health data collected from wearable devices. For example, patients may prefer to interact with a virtual advocate to review discharge instructions ("Louis" in Project Re-Engineered Discharge) when personalized to their demographics and health literacy level. ${ }^{30-32}$ Patients may choose to upload step counts from wearable devices so that clinicians can monitor activity goals in preparation for discharge and while recovering afterwards. When supported in these ways, acute care patient portals allow patients to have more meaningful interactions with clinicians about diagnoses, treatments, prognosis, and goals for recovery.

The main challenges we identified include balancing interactions with technology and clinicians, ensuring clinicians understand how patients from different socioeconomic backgrounds use existing and newer technology to enhance self-management, assessing health and technology literacy, and understanding individual preferences for sharing patient-generated health data. Importantly, we must remain vigilant that patients will express concern about overdependence on technology, especially if it detracts from in-person interaction; our panelists emphasized that technology should never replace "human touch." 
TABLE 1. Opportunities and Challenges for Improving the Acute and Post-Acute Care Patient Experience

\begin{tabular}{|c|c|c|c|}
\hline Themes & Opportunities & Challenges & Examples \\
\hline \multicolumn{4}{|c|}{ Cognitive Support - "Can help enhance communication in your own language, not just the language of the clinician." } \\
\hline \multirow{2}{*}{$\begin{array}{l}\text { Acclimatization and } \\
\text { assimilation }\end{array}$} & $\begin{array}{l}\text { Understand policies, procedures, unit protocols, the } \\
\text { rights of patients, families, and care partners, and } \\
\text { clinical staff roles }\end{array}$ & $\begin{array}{l}\text { Ensure hospital information is accurate, up-to-date, and } \\
\text { easy to understand }\end{array}$ & $\begin{array}{l}\text { View videos to orient patients, families, and care partners } \\
\text { upon admission to the intensive care unit }\end{array}$ \\
\hline & $\begin{array}{l}\text { Timely and relevant clinical updates for patients and } \\
\text { care partners, including bedside and distant family } \\
\text { members }\end{array}$ & $\begin{array}{l}\text { Address cognitive burden from information overload } \\
\text { and alert fatigue; ensure security and privacy when } \\
\text { expanding access to care partners }\end{array}$ & $\begin{array}{l}\text { Designate access for proxies when patients are incapaci- } \\
\text { tated; view updated schedule of planned procedures and } \\
\text { imaging studies }\end{array}$ \\
\hline \multirow{2}{*}{$\begin{array}{l}\text { Self-education and } \\
\text { preparation }\end{array}$} & $\begin{array}{l}\text { Enable on-demand access to personal health infor- } \\
\text { mation and educational materials linked to patient's } \\
\text { problems, medications, and test results in the EHR }\end{array}$ & $\begin{array}{l}\text { Ensure clinical information is optimally presented for } \\
\text { all health literacy levels and languages; ensure EHR is } \\
\text { routinely updated }\end{array}$ & $\begin{array}{l}\text { View educational content specific to patient's medical } \\
\text { conditions, medications, and test results }\end{array}$ \\
\hline & $\begin{array}{l}\text { Review standardized checklists and guides to prepare } \\
\text { for complex clinical conversations with clinicians and } \\
\text { transitions to and from the hospital }\end{array}$ & $\begin{array}{l}\text { Ensure patients of all literacy levels can easily access, } \\
\text { navigate, and comprehend information }\end{array}$ & $\begin{array}{l}\text { Prompt patient to review a predischarge checklist prior to } \\
\text { their expected discharge date }\end{array}$ \\
\hline \multicolumn{4}{|c|}{ Respect and Boundaries - "There is a happy compromise, but info should be delivered and utilized in a way that you would want." } \\
\hline \multirow{2}{*}{$\begin{array}{l}\text { Individual learning } \\
\text { styles }\end{array}$} & $\begin{array}{l}\text { Support individual preferences for using interactive } \\
\text { features (high-definition video, intelligent personal } \\
\text { assistants, multidimensional touch) }\end{array}$ & $\begin{array}{l}\text { Balance online and in-person interactions with clini- } \\
\text { cians; minimize overdependence on technology }\end{array}$ & $\begin{array}{l}\text { Perform automated teach-back in patients' preferred } \\
\text { language and format (text, audio, video) }\end{array}$ \\
\hline & $\begin{array}{l}\text { Improve comprehension for visual, auditory, and tactile } \\
\text { learners; reinforce learning by using digital media } \\
\text { (graphics, video tutorials, avatars) }\end{array}$ & $\begin{array}{l}\text { Ensure clinicians understand how patients use the portal } \\
\text { to engage in learning and care processes (electronically } \\
\text { signing consent form) }\end{array}$ & $\begin{array}{l}\text { Provide the option of viewing an educational video or } \\
\text { taking an interactive tutorial about a procedure prior to } \\
\text { meeting with the surgeon }\end{array}$ \\
\hline \multirow[t]{2}{*}{ Personalization } & $\begin{array}{l}\text { Tailor educational content, features, and functionality } \\
\text { to patient's age, gender, primary language, and health } \\
\text { literacy level; provide cultural context in interactive } \\
\text { self-care instructions }\end{array}$ & $\begin{array}{l}\text { Assess health and technology literacy of patients; } \\
\text { respect time necessary to review and understand clinical } \\
\text { information prior to making decisions }\end{array}$ & $\begin{array}{l}\text { Provide options for selecting a virtual or live interpreter } \\
\text { based on the patient's primary language when reviewing } \\
\text { informed consent forms }\end{array}$ \\
\hline & $\begin{array}{l}\text { Connect to personal wearable devices (activity tracker) } \\
\text { to upload patient-generated health data for medical } \\
\text { decision-making }\end{array}$ & $\begin{array}{l}\text { Understand individual preferences and comfort with } \\
\text { sharing patient-generated health data }\end{array}$ & $\begin{array}{l}\text { Prompt patient to connect a bluetooth activity tracker prior } \\
\text { to discharge to monitor health data (step-counts, heart } \\
\text { rate) during recovery }\end{array}$ \\
\hline
\end{tabular}

Patient and Family Empowerment - "Weekends are scary. It is hard to find someone [with whom] to communicate. You are watching your loved one get passed from team to team. You HOPE that the last care team thinks what the last team thought."

\begin{tabular}{|c|c|c|c|}
\hline \multirow{2}{*}{$\begin{array}{l}\text { Patient-centered } \\
\text { communication }\end{array}$} & $\begin{array}{l}\text { Support real time (video conferencing) and asyn- } \\
\text { chronous (secure messaging) communication among } \\
\text { patients, care partners, and care team members }\end{array}$ & $\begin{array}{l}\text { Encourage appropriate use of communication tools; } \\
\text { minimize conversational silos among clinicians }\end{array}$ & $\begin{array}{l}\text { Synchronize message recipients to current care team role } \\
\text { assignments in the EHR }\end{array}$ \\
\hline & $\begin{array}{l}\text { Display pictures, names, roles, and availability of all care } \\
\text { team members }\end{array}$ & $\begin{array}{l}\text { Maintain accuracy of care team member identities and } \\
\text { availability }\end{array}$ & $\begin{array}{l}\text { Prompt the patient to add their ambulatory specialist to } \\
\text { the care team }\end{array}$ \\
\hline Transparency & $\begin{array}{l}\text { Share clinical information and documentation typically } \\
\text { maintained by clinicians (progress notes, sign-outs) } \\
\text { with patients and care partners to facilitate shared } \\
\text { decision-making; hold clinicians accountable to a single } \\
\text { care plan at shift-change/handoff }\end{array}$ & $\begin{array}{l}\text { Overcome fear of sharing information in the EHR entered } \\
\text { by clinicians; acknowledge patients as equal partners; } \\
\text { manage expectations about the diagnostic process and } \\
\text { therapeutic options when multiple clinicians are involved } \\
\text { or team members change }\end{array}$ & $\begin{array}{l}\text { Invite patients, care partners, and family members to } \\
\text { review standardized handoff information (I-PASS) from the } \\
\text { EHR at shift change and handoffs }\end{array}$ \\
\hline Real-time feedback & $\begin{array}{l}\text { Provide tools to react to or rate newly displayed informa- } \\
\text { tion and report safety concerns to the care team }\end{array}$ & $\begin{array}{l}\text { Address patient and care partner concerns quickly and } \\
\text { respectfully; support patients who fear retaliation for } \\
\text { voicing complaints }\end{array}$ & $\begin{array}{l}\text { Invite patients to provide input about their expected } \\
\text { discharge date and options for skilled nursing facilities }\end{array}$ \\
\hline
\end{tabular}

NOTE: Abbreviations: EHR, electronic health record; I-PASS; illness severity, patient summary, action list, situational awareness and contingency plans, and synthesis by receiver.

\section{Patient and Family Empowerment}

The opportunities identified include promoting patient-centered communication by supporting a real-time and asynchronous dialogue among patients, care partners, and care team members (including ambulatory clinicians) while minimizing conversational silos ${ }^{4,33}$; displaying names, roles, and pictures of all care team members ${ }^{4,34}$; fostering transparency by sharing clinician documentation in progress notes and sign-outs ${ }^{35}$; ensuring accountability for a single plan of care spanning shift changes and handoffs, and providing a mech- anism to enable real-time feedback.

Hospitalization can be a vulnerable and isolating experience, perpetuated by a lack of timely and coordinated communication with the care team. We identified opportunities to mitigate anxiety by promoting shared understanding when questions require input from multiple clinicians, when team members change, or when patients wish to communicate with their longitudinal ambulatory providers. ${ }^{4,34}$ For example, inviting patients to review clinicians' progress notes should stimulate more open and meaningful commu- 
TABLE 2. Goals and Recommendations for Institutions, Clinicians, and Vendors Implementing Acute Care Patient Portals to Support, Respect, and Empower Hospitalized Patients

\begin{tabular}{|c|c|c|}
\hline & Goals & Recommendations \\
\hline \multirow[t]{2}{*}{ Institutions } & Comply with federal regulations (CARE Act) & $\begin{array}{l}\text { Develop sustainable strategy to identify care partners for both current enrollees and nonenrollees of institutional patient } \\
\text { portals upon hospital admission }\end{array}$ \\
\hline & $\begin{array}{l}\text { Maximize value-based reimbursement via key } \\
\text { programs (HRRP, HVBP, MACRA) }\end{array}$ & $\begin{array}{l}\text { Ensure acute care patient portals address key patient experiences of care domains that are targets of quality reporting: } \\
\text { communication with MD and RN, communication about medications, and discharge information and instructions }\end{array}$ \\
\hline \multirow[t]{2}{*}{ Clinicians } & $\begin{array}{l}\text { Enhance patient-centered bedside rounding } \\
\text { experience }\end{array}$ & $\begin{array}{l}\text { Encourage reliable use of core EHR functionality (problem-based charting, care team role assignments) by clinicians to tailor } \\
\text { self-management education and facilitate accurate identification of care team members for patients via EHR-linked acute } \\
\text { care patient portals }\end{array}$ \\
\hline & $\begin{array}{l}\text { Extend reach of concurrent transitional care } \\
\text { interventions }\end{array}$ & $\begin{array}{l}\text { Encourage transitional teams to empower patients and care partners to use acute care patient portals to participate in dis- } \\
\text { charge preparation, disease management, medication reconciliation, and self-management education during hospitalization } \\
\text { and after discharge }\end{array}$ \\
\hline \multirow[t]{2}{*}{ Vendors } & $\begin{array}{l}\text { Enhance and develop offerings to support } \\
\text { broad-based patient engagement }\end{array}$ & $\begin{array}{l}\text { Work with patient networks and advocacy groups to ensure existing and forthcoming functionality, meaningfully support } \\
\text { language, health literacy, access, and technology barriers for patients, family caregivers, and care partners }\end{array}$ \\
\hline & $\begin{array}{l}\text { Ensure support for technology standards and } \\
\text { new requirements under MACRA }\end{array}$ & $\begin{array}{l}\text { Use open APIs and emerging standards (FHIR) to facilitate data exchange with third-party applications that address current } \\
\text { gaps in functionality (eg, applications capturing patient reported outcomes) }\end{array}$ \\
\hline
\end{tabular}

NOTE: Abbreviations: API, Application Programming Interface; CARE, Caregiver Advise Record and Enable Act; EHR, electronic health record; FHIR, Fast Healthcare Interoperability Resources; HRRP, Hospital Readmission Reduction Program; HVBP, Hospital Value-Based Purchasing Program; MACRA, Medicare Access and CHIP Reauthorization Act (Merit-Based Incentive Payment System, Alternative Payment Models).

nication. ${ }^{35}$ Furthermore, requesting that patients state their wishes, preferences, and goals could improve overall concordance with care team members. ${ }^{36,37}$ Empowering patients and care partners to voice their concerns, particularly those related to miscommunication, may mitigate harm propagated by handoffs, shift work, and weekend coverage. ${ }^{38,39}$ While reporting safety concerns represents a novel mechanism to augment medical-error reporting by clinicians alone, ${ }^{23,40}$ this strategy will be most effective when aligned with standardized communication initiatives (I-PASS) that have been proven to reduce medical errors and preventable adverse events and are being implemented nationally. ${ }^{41}$ Finally, by leveraging tools that facilitate instantaneous feedback, patients can be empowered to react to their plan (ranking skilled nursing facility options) as it is developed.

The main challenges we identified include managing expectations regarding the use of communication tools, accurately and reliably identifying care team members in the $\mathrm{EHR},{ }^{34}$ acknowledging patients as equal partners, ensuring patients receive a consistent message about diagnoses and therapies during handoffs and when multiple consultants have conflicting opinions about the plan, ${ }^{37}$ and addressing patient concerns fairly and respectfully.

\section{RECOMMENDATIONS AND CONCLUSIONS}

As hospitals start implementing acute care patient portals, how should we prepare? We offer several recommendations to guide key stakeholders (Table 2). Institutions would benefit from aligning implementation with forthcoming regulations and value-based reimbursement initiatives. Clinicians would benefit from using acute care patient portals to enhance concurrent patient engagement initiatives (patient-centered bedside rounds, transitional care interventions). Vendors would benefit by recognizing that current offerings fall short of the desired features and functionality, from partnering formally with patients and advocacy groups to enhance their offerings, especially when incorporating new technologies (artificial intelligence); and from enabling the use of open-application programming interfaces and emerging technology standards that allow third-party applications addressing existing gaps to exchange data quickly and securely. ${ }^{42}$

In summary, the patient-centered themes we identified serve as guiding principles for institutions, clinicians, and vendors who wish to use patient portals to improve the acute and postacute care patient experience. One central message resonates: Patients do not simply want access to their health information and the ability to communicate with the clinicians who furnish this information; they want to feel supported, respected, and empowered when doing so. It is only through partnership with patients and their advocates that we can fully realize the impact of digital technologies when patients are in their most vulnerable state.

\section{Acknowledgments}

The authors thank their colleagues and the patient and family advocates who contributed to this body of work as part of the Acute Care Patient Portal Task Force and conference: Brittany Couture; Ronen Rozenblum, PhD, MPH; Jennifer Prey, MPhil, MS, PhD; Kristin O'Reilly, RN, BSN, MPH; Patricia Q. Bourie, RN, MS, Cindy Dwyer, RN, BSN, S; Ryan Greysen, MD, MHS, MA; Jeffery Smith, MPP; Michael Gropper, MD, PhD; Patricia Dykes, RN, PhD; Martha B. Carnie; Jeffrey W. Mello; and Jane Webster.

Disclosure: Anuj K. Dalal, MD, David W. Bates, MD, MSc, and Sarah Collins, RN, $\mathrm{PhD}$, are responsible for the conception or design of the work; acquisition, analysis, or interpretation of data; drafting the work or revising it critically for important intellectual content; and final approval of the version to be published. The authors agree to be accountable for all aspects of the work and to ensure that questions related to the accuracy or integrity of the work are appropriately investigated and resolved. This work was supported by a grant from the Gordon and Betty Moore Foundation ([GBMF]\#4993). GBMF had no role in the design or conduct of the study; the collection, analysis, or 
interpretation of data; or preparation or review of the manuscript. The findings and conclusions in this report are those of the authors and do not necessarily represent the official position of GBMF. The authors report no conflicts of interest.

\section{References}

1. Sarkar U, Bates DW. Care partners and online patient portals. JAMA 2014:311(4):357-358

2. Grando MA, Rozenblum R, Bates DW, eds. Information Technology for Patient Empowerment in Healthcare, 1st Edition. Berlin: Walter de Gruyter Inc.; 2015.

3. Kelly MM, Hoonakker PLT, Dean SM. Using an inpatient portal to engage families in pediatric hospital care. J Am Med Inform Assoc. 2016;24(1):153-161.

4. Dalal AK, Dykes PC, Collins S, et al. A web-based, patient-centered toolkit to engage patients and caregivers in the acute care setting: A preliminary evaluation. J Am Med Inform Assoc. 2016;23(1):80-87.

5. Prey JE, Restaino S, Vawdrey DK. Providing hospital patients with access to their medical records. AMIA Annu Symp Proc. 2014;2014:1884-1893.

6. Herrin J, Harris KG, Kenward K, Hines S, Joshi MS, Frosch DL. Patient and family engagement: A survey of US hospital practices. BMJ Qual Saf. 2016;25(3): 182-189.

7. Tom JO, Mangione-Smith R, Solomon C, Grossman DC. Integrated personal health record use: Association with parent-reported care experiences. Pediatrics. 2012;130(1):e183-e190

8. Centers for Medicare \& Medicaid Services (CMS), HHS. Medicare and Medicaid Programs; Electronic Health Record Incentive Program-Stage 2. Federal Register Final Rule. Sect. 170; 2012. https://www.federalregister.gov/ documents/2012/03/07/2012-4443/medicare-and-medicaid-programs-electronic-health-record-incentive-program-stage-2. Accessed March 1, 2017.

9. Centers for Medicare \& Medicaid Services (CMS), HHS. Medicare program; merit-based incentive payment system (MIPS) and alternative payment model (APM) incentive under the physician fee schedule, and criteria for phy sician-focused payment models. Final rule with comment period. Fed Regist 2016;81(214):77008-77831

10. Prey JE, Woollen J, Wilcox L, et al. Patient engagement in the inpatient setting: A systematic review. J Am Med Informat Assoc. 2014;21(4):742-750.

11. Ludwin S, Grevsen SR. Use of smartphones and mobile devices in hospitalized patients: Untapped opportunities for inpatient engagement. J Hosp Med. 2015;10(7):459-461.

12. Coleman EA. Family caregivers as partners in care transitions: The caregiver advise record and enable act. J Hosp Med. 2016;11(12):883-885.

13. Kaziunas E, Hanauer DA, Ackerman MS, Choi SW. Identifying unmet informational needs in the inpatient setting to increase patient and caregiver engagement in the context of pediatric hematopoietic stem cell transplantation. J Am Med Inform Assoc. 2016;23(1):94-104.

14. Woollen J, Prey J, Wilcox L, et al. Patient experiences using an inpatient personal health record. Appl Clin Inform. 2016;7(2):446-460.

15. Irizarry T, DeVito Dabbs A, Curran CR. Patient portals and patient engagement: A state of the science review. J Med Internet Res. 2015;17(6):e148. doi:10.2196/ jmir.4255.

16. Vawdrey DK, Wilcox LG, Collins SA, et al. A tablet computer application for patients to participate in their hospital care. AMIA Annu Symp Proc. 2011;2011:1428-1435

17. Collins SA, Rozenblum R, Leung WY, et al. Acute care patient portals: A qualitative study of stakeholder perspectives on current practices. J Am Med Inform Assoc 2016;24(e1):e9-e17.

18. Berger Z, Flickinger TE, Pfoh E, Martinez KA, Dy SM. Promoting engagement by patients and families to reduce adverse events in acute care settings: A systematic review. BMJ Qual Saf. 2014;23(7):548-555.

19. Forster AJ, Murff HJ, Peterson JF, Gandhi TK, Bates DW. The incidence and severity of adverse events affecting patients after discharge from the hospital. Ann Intern Med. 2003;138(3):161-167.
20. Griffin A, Skinner A, Thornhill J, Weinberger M. Patient Portals: Who uses them? What features do they use? And do they reduce hospital readmissions? Appl Clin Inform. 2016;7(2):489-501.

21. O'Leary KJ, Lohman ME, Culver E, Killarney A, Randy Smith G Jr, Liebovitz DM. The effect of tablet computers with a mobile patient portal application on hospitalized patients' knowledge and activation. J Am Med Inform Assoc. 2016;23(1):159-165.

22. O'Leary KJ, Sharma RK, Killarney A, et al. Patients' and Healthcare Providers' Perceptions of a Mobile Portal Application for Hospitalized Patients. BMC Med Inform Decis Mak. 2016;16(1):123.

23. Pell JM, Mancuso M, Limon S, Oman K, Lin CT. Patient access to electronic health records during hospitalization. JAMA Intern Med. 2015;175(5):856-858.

24. Brown SM, Aboumatar HJ, Francis L, et al. Balancing digital information-sharing and patient privacy when engaging families in the intensive care unit. J Am Med Inform Assoc. 2016;23(5):995-1000.

25. Krishna S, Francisco BD, Balas EA, et al. Internet-enabled interactive multimedia asthma education program: A randomized trial. Pediatrics. 2003;111(3):503-510.

26. Fox MP. A systematic review of the literature reporting on studies that examined the impact of interactive, computer-based patient education programs. Patient Educ Couns. 2009;77(1):6-13.

27. Morgan ER, Laing K, McCarthy J, McCrate F, Seal MD. Using tablet-based technology in patient education about systemic therapy options for early-stage breast cancer: A pilot study. Curr Oncol. 2015;22(5):e364-e369.

28. Nehme J, El-Khani U, Chow A, Hakky S, Ahmed AR, Purkayastha S. The use of multimedia consent programs for surgical procedures: A systematic review. Surg Innov. 2013;20(1):13-23.

29. Waller A, Forshaw K, Carey M, et al. Optimizing patient preparation and surgical experience using eHealth technology. JMIR Med Inform. 2015;3(3):e29.

30. Abbott MB, Shaw P. Virtual nursing avatars: Nurse roles and evolving concepts of care. Online J Issues Nurs. 2016;21(3):7.

31. Cawthon C, Walia S, Osborn CY, Niesner KJ, Schnipper JL, Kripalani S. Improving care transitions: The patient perspective. J Health Commun. 2012;17 Suppl 3: 312-324.

32. Bickmore TW, Pfeifer LM, Byron D, et al. Usability of conversational agents by patients with inadequate health literacy: Evidence from two clinical trials. J Health Commun. 2010;15 Suppl 2:197-210.

33. Dalal AK, Schnipper J, Massaro A, et al. A web-based and mobile patient-centered "microblog" messaging platform to improve care team communication in acute care. J Am Med Inform Assoc. 2016;24(e1):e178-e184.

34. Dalal AK, Schnipper JL. Care team identification in the electronic health record: A critical first step for patient-centered communication. J Hosp Med. 2016;11(5):381-385

35. Feldman HJ, Walker J, Li J, Delbanco T. OpenNotes: Hospitalists' challenge and opportunity. J Hosp Med. 2013;8(7):414-417.

36. Figueroa JF, Schnipper JL, McNally K, Stade D, Lipsitz SR, Dalal AK. How often are hospitalized patients and providers on the same page with regard to the patient's primary recovery goal for hospitalization? J Hosp Med. 2016;11(9):615-619.

37. Khan A, Rogers JE, Forster CS, Furtak SL, Schuster MA, Landrigan CP. Communication and shared understanding between parents and resident-physicians at night. Hosp Pediatr. 2016;6(6):319-329.

38. Khan A, Baird J, Rogers JE, et al. Parent and provider experience and shared understanding after a family-centered nighttime communication intervention. Acad Pediatr. 2017;17(4):389-402

39. Khan A, Coffey M, Litterer KP, et al. Families as partners in hospital error and adverse event surveillance. JAMA Pediatr. 2017;171(4):372-381.

40. Kelly MM, Hoonakker PLT, Dean SM. Using an inpatient portal to engage families in pediatric hospital care. J Am Med Inform Assoc. 2016;24(1):153-161.

41. Starmer AJ, Spector ND, Srivastava R, et al. Changes in medical errors after implementation of a handoff program. N Engl J Med. 2014;371(19):1803-1812.

42. Mandl KD, Kohane IS. A 21st-century health IT system-creating a real-world information economy. N Engl J Med. 2017;376(20):1905-1907. 